\title{
(2) OPEN ACCESS \\ Care-pathways for patients presenting to emergency ambulance services with self-harm: national survey
}

\author{
Mohammed Gaber Zayed (ㄱ) , 'Victoria Williams, ${ }^{2}$ Alexander Charles Glendenning, ${ }^{1}$ \\ Jenna Katherine Bulger 다, ${ }^{1}$ Tom Hewes, ${ }^{3}$ Alison Porter, ${ }^{1}$ Helen Snooks, ${ }^{1}$ A John ${ }^{1}$
}

\begin{abstract}
Handling editor Caroline Leech
\end{abstract}

Additional material is published online only. To view please visit the journal online (http://dx.doi.org/10.1136/ emermed-2019-208967).

'Swansea University Medical School, Swansea University, Swansea, UK

${ }^{2}$ Hillary Rodham Clinton School of Law, Swansea University,

Swansea, UK

${ }^{3}$ College of Human and Health Sciences, Swansea University, Swansea, UK

\section{Correspondence to} Dr A John, Swansea University Medical School, Swansea University, Swansea, UK: a.john@swansea.ac.uk

Received 24 July 2019 Revised 18 June 2020 Accepted 24 June 2020 Published Online First 3 September 2020
Check for updates

(C) Author(s) (or their employer(s)) 2020. Re-use permitted under CC BY-NC. No commercial re-use. See rights and permissions. Published by BMJ.

To cite: Zayed MG,

Williams V, Glendenning AC, et al. Emerg Med J

2020:37:752-755

\begin{abstract}
Background Self-harm is among the top five causes of acute hospital admissions and ambulance clinicians are often the first point of contact. However, the Emergency Department (ED) may not be the most appropriate place of care and little is known about the existence or nature of alternative pathways available to UK ambulance services. This survey describes the current management pathways used by ambulance services for patients who have selfharmed.

Methods A structured questionnaire was sent to all UK ambulance services by email and followed up by telephone in 2018. Three independent researchers (two clinical) coded responses which were analysed thematically.
\end{abstract}

Results All 13 UK ambulance services responded to the survey: nine by email and four by telephone interview. Two services reported a service-wide protocol for managing people presenting with self-harm, with referral to mental health crisis team available as an alternative to conveyance to ED, following on-scene psychosocial assessment. Four services reported local pathways for managing mental health patients which included care of patients who had self-harmed. Four services reported being in the process of developing pathways for managing mental health patients. Six services reported no service-wide nor local pathways for managing self-harm patients. No robust evaluation of new care models was reported.

Conclusion Practice in ambulance services in the UK is variable, with a minority having a specific clinical pathway for managing self-harm, with an option to avoid ED. New pathways for patients who have self-harmed must be evaluated in terms of safety, clinical and costeffectiveness.

\section{INTRODUCTION}

Self-harm is one of the top causes of acute medical admission which has an impact on emergency care provision in the UK and internationally. ${ }^{1}$ Ambulance clinicians are often the first point of contact for patients who have self-harmed. The nature of this encounter affects immediate outcomes and future help-seeking behaviour. ${ }^{1-3}$

Although there is a lack of evidence about safety and effectiveness, UK national guidance includes recommendations that ambulance trusts, ED and mental health trusts should work together to develop alternative care pathways for ambulance staff to implement for people who have selfharmed. ${ }^{4}$ In Australia, New Zealand and Sweden initiatives have been introduced to improve care for patients who have self-harmed. ${ }^{56}$

\section{Key messages}

What is already known on this subject

- Little is known about the existence or nature of alternative pathways (avoiding ED attendance) available to UK ambulance services.

- Studies, mainly in ED, showed a lack of relevant clinical policies and training for ambulance clinicians managing those who self-harm.

- Evidence about safety and effectiveness is lacking.

What this study adds

- In this survey of all ambulance services in the UK, we found a variability in managing patients who have self-harmed.

- A minority of UK ambulance services have a specific clinical pathway for managing selfharm presentations with ED avoidance options.

- There is a need for evaluation of any pathways in terms of safety, on-going care, costeffectiveness and acceptability.

In this study, we describe emergency ambulance practice across the UK for patients who have selfharmed; whether a routine, service-wide protocol was in place and if local pathways existed.

\section{METHODS}

We developed a structured questionnaire (online supplementary appendix 1) based on a literature review, ${ }^{23}$ piloted it with paramedic colleagues and incorporated their suggestions.

Between February and April 2018, we sent a questionnaire, information sheet and consent form to the nominated lead for mental healthcare at each ambulance service (AS) trust in the UK. Respondents could return questionnaires by email or be interviewed by telephone.

AJ, HS and MZ analysed responses using a thematic approach. ${ }^{8}$

As this study was a survey of usual service provision, there was no requirement for ethical approval. Patients or the public were not involved in the design, conduct, reporting or dissemination plans of this survey.

\section{RESULTS}

All 13 UK AS responded to the survey, nine by email and four by telephone interview. Responses are summarised in table 1. 
Table 1 Summary of ambulance service (AS) survey responses

\begin{tabular}{|c|c|c|c|c|}
\hline AS & Respondent & Trust wide protocol in place & Local pathways in place/being developed & $\begin{array}{l}\text { Evaluating self-harm } \\
\text { management }\end{array}$ \\
\hline 1 & Area clinical lead & No. & $\begin{array}{l}\text { No. } \\
\text { Working to develop alternate mental health pathways. } \\
\text { Not self-harm specific. }\end{array}$ & No. \\
\hline 2 & Mental health lead nurse & $\begin{array}{l}\text { Yes. } \\
\text { Mental health protocol including self- } \\
\text { harm with options to convey to ED or } \\
\text { refer to mental health crisis service } \\
\text { as appropriate. }\end{array}$ & $\begin{array}{l}\text { Yes, in certain areas, in partnership with local mental } \\
\text { health trust. } \\
\text { Variable hours of operation. }\end{array}$ & $\begin{array}{l}\text { No. } \\
\text { Planned for } 2018\end{array}$ \\
\hline 3 & Mental health strategy lead & No. & $\begin{array}{l}\text { Yes. } \\
\text { Triage of } 999 \text { calls and response by cars with paramedics } \\
\text { and mental health nurses. } \\
\text { In partnership with local mental health trust and approved } \\
\text { mental health professionals in some areas. } \\
\text { Not self-harm specific. }\end{array}$ & No. \\
\hline 4 & Mental health clinical lead & $\begin{array}{l}\text { Yes. } \\
\text { No further details given. }\end{array}$ & No. & No. \\
\hline 5 & Mental health project lead & No. & $\begin{array}{l}\text { Yes. } \\
\text { Referral project in which } 999 \text { calls are triaged in the } \\
\text { dispatch centre and patients are signposted when } \\
\text { appropriate to a Mental Health Crisis Team in place of } \\
\text { sending an emergency ambulance. } \\
\text { Also, a street triage scheme in partnership with local } \\
\text { police and mental health service. } \\
\text { Not self-harm specific. } \\
\text { Highlighted that immediate medical need 'trumps' care of } \\
\text { mental health problems. }\end{array}$ & No. \\
\hline 6 & $\begin{array}{l}\text { Mental health nurse } \\
\text { consultant }\end{array}$ & $\begin{array}{l}\text { No. } \\
\text { Self-harm would trigger the use of a } \\
\text { specific risk assessment tool by the } \\
\text { crew on scene. The primary focus is } \\
\text { on treatment of physical injury and } \\
\text { then onward referral to a crisis team } \\
\text { or if necessary, conveyance to ED for } \\
\text { psychiatric liaison support. }\end{array}$ & No. & No. \\
\hline 7 & Head of clinical operations & $\begin{array}{l}\text { No. } \\
\text { Have access to trust-wide mental } \\
\text { health crisis teams if injuries are } \\
\text { not serious enough to require ED } \\
\text { treatment. No specific protocol for } \\
\text { self-harm. }\end{array}$ & No. & Yes. \\
\hline 8 & $\begin{array}{l}\text { Consultant paramedic, mental } \\
\text { health lead }\end{array}$ & No. & $\begin{array}{l}\text { No. } \\
\text { Piloting having mental health nurses in ambulance control } \\
\text { room. } \\
\text { Not self-harm specific. }\end{array}$ & No. \\
\hline 9 & $\begin{array}{l}\text { Mental health professional } \\
\text { lead }\end{array}$ & No. & $\begin{array}{l}\text { No. } \\
\text { Triage in the ambulance call centre with options - } \\
\text { conveyance to ED, 'see and treat' (ie, attendance but } \\
\text { non-conveyance), referral to crisis team, dependent on } \\
\text { local service availability. Patients who have overdosed are } \\
\text { automatically taken to ED. } \\
\text { Paramedics have a crew line to speak to mental health } \\
\text { nurses. Introduced in } 2016 \text {. They are available } 24 / 7 \text { but 'it } \\
\text { is a small team so might not always be able to speak to } \\
\text { someone'. } \\
\text { Not self-harm specific. }\end{array}$ & No. \\
\hline 10 & $\begin{array}{l}\text { Mental health strategic } \\
\text { advisor }\end{array}$ & No. & $\begin{array}{l}\text { No. } \\
\text { Callers are triaged by the 'clinical hub' in the call centre } \\
\text { to appropriate response-referred to ED/minor injures } \\
\text { unit if required for treatment of injuries, with follow-up } \\
\text { by mental health service if patients already known, or to } \\
\text { general practitioner if not. Limited access to mental health } \\
\text { professionals in the Clinical Hub and to mental health } \\
\text { crisis teams has been challenging. } \\
\text { Looking to link ambulance service and mental health } \\
\text { records. }\end{array}$ & $\begin{array}{l}\text { Auditing self-harm data on } \\
\text { monthly basis, this has been } \\
\text { updated in February } 2018 \text { to } \\
\text { include only patients left at home. }\end{array}$ \\
\hline
\end{tabular}




\begin{tabular}{|c|c|c|c|c|}
\hline AS & Respondent & Trust wide protocol in place & Local pathways in place/being developed & $\begin{array}{l}\text { Evaluating self-harm } \\
\text { management }\end{array}$ \\
\hline 11 & Interim medical director & No. & $\begin{array}{l}\text { No. } \\
\text { Currently setting up street triage project with paramedic, } \\
\text { police officer and psychiatric nurse to rapidly assess } \\
\text { patients in the prehospital setting. Challenging to } \\
\text { secure agreement of hospital Trust to provide a qualified } \\
\text { psychiatric nurse to undertake clinical triage which is } \\
\text { outside the scope of paramedic practice. }\end{array}$ & No. \\
\hline 12 & Clinical governance manager & $\begin{array}{l}\text { No. } \\
\text { Working on a mental health policy } \\
\text { and education package which } \\
\text { includes a self-harm section. } \\
\text { Physical health is considered first, if } \\
\text { injuries are severe or life threatening, } \\
\text { the patient is taken to ED. }\end{array}$ & $\begin{array}{l}\text { No. } \\
\text { Working on a referral pathway called Distress Brief } \\
\text { Intervention being developed with primary care, ED, police } \\
\text { and third sector partners (4-year pilot). }\end{array}$ & No. \\
\hline 13 & Head of clinical practice & $\begin{array}{l}\text { No. } \\
\text { Physical injuries take priority and } \\
\text { often indicate need for ED care. }\end{array}$ & $\begin{array}{l}\text { Yes. } \\
\text { Have local mental health triage teams consisting of a } \\
\text { mental health nurse, a paramedic and a police officer. } \\
\text { Hours of operation vary by area. } \\
\text { In partnership with police, CCG and mental health trust. } \\
\text { Not self-harm specific. }\end{array}$ & Currently auditing self-harm data. \\
\hline
\end{tabular}

CCG, Clinical Commissioning Groups.

Only two services (AS 2 and 4) reported having a servicewide protocol for managing patients who have self-harmed. Four services (AS 2, 3, 5 and 13) reported local pathways for managing patients who have self-harmed. AS 2 had pathways which included an option of referral to mental health crisis teams as an alternative to conveyance to ED when appropriate; pathways operated limited hours depending on availability of the local mental health Trust. AS 3, 5 and 13 described local pathways for managing 'mental health patients' which included self-harm presentations. Both services had a 'street triage' option in some areas to dispatch a team which included paramedic, mental health nurse and police officer to emergency calls for patients who have self-harmed.

Four services (AS 1, 5, 11 and 12) reported that they were developing pathways and protocols. AS 1 provided little detail. AS 5 described a project where callers would be triaged in the call centre and referred to a mental health crisis team if appropriate. AS 11 was developing a street triage project with a response team comprising paramedic, police officer and psychiatric nurse to assess patients in the pre-hospital setting. AS 12 reported developing a referral pathway which they hoped to implement fully by 2021; once established that there is no immediate threat to life, patients would be referred through the pathway avoiding ED admission; a 24-hour service in partnership with police, NHS Health Boards, ED and general practitioners (GPs).

Six services (AS 6, 7, 8, 9, 10 and 11) had no current servicewide nor local pathways for the management of patients who have self-harmed. Despite this, each of these services provided details of service-wide or local initiatives relevant to this group including: use of a self-harm risk assessment tool; access to mental health crisis teams for those who do not need to travel to ED for care of injuries; availability of mental health nurses in the ambulance call centre; or clinical hub in the call centre with option to refer to ED or minor injuries unit for treatment of injuries with follow-up by mental health service or GPs. Several services highlighted the prioritisation of care of physical injuries.

AS 2, 3, 6, 8, 9 and 10 highlighted the need for training and education for ambulance clinicians on underlying causes and the management of patients who have self-harmed.
Two services reported audits of care of patients who have selfharmed (AS 10, AS 13); one service reported evaluation activity (AS 7) and another reported plans for evaluation (AS 2).

\section{DISCUSSION}

We found variation and a lack of clarity, across and within AS, in the provision of care to patients who have self-harmed. Alternative pathways for those patients started in some services in the ambulance call centre through signposting or targeted responses; and sometimes on scene, by paramedics who were able to assess and triage patients to ED or community referral or by a 'street triage' team, in partnership with mental health providers and the police. Where pathways were in place their operation was dependent on availability of mental health professionals, so access was reported to be variable. Respondents highlighted the need for training and education covering the underlying reasons and management of self-harm presentations, to enable ambulance clinicians to consider options of ED avoidance confidently. With such a lack of underpinning evidence for new models of care it was surprising that very little evaluation was in place.

\section{Strengths and limitations}

We had a $100 \%$ response to this survey but there was a lack of detail in some responses. AS may have developed new pathways since this survey was conducted.

\section{Implications}

Despite UK national guidelines indicating the need for appropriate care pathways for ambulance clinicians to refer on people who self-harm, ${ }^{4} 9$ services are still a long way from having universal access to such pathways. There are various challenges to achieving this. Each AS works across the footprint of multiple mental health providers, meaning that a range of local arrangements needs to be set up and maintained. Emergency AS operate 24 hours a day, while many local mental health responses may be available for much more restricted times.

There is currently a paucity of evidence about the safety and effectiveness of care delivered by emergency AS for patients who 
have self-harmed. ${ }^{410}$ While three of the services were auditing self-harm data none of the pathways was being evaluated at the time of the survey in terms of uptake, safety, clinical or costeffectiveness. It is important that any new pathways undergo robust evaluation to assess safety, clinical and cost-effectiveness.

Contributors JJ, TH, AP, HS and AJ developed the questionnaire for the survey. VW and AG contacted ambulance services and conducted telephone interviews and collected the data. MGZ, HS and AJ contributed in literature search, design of the manuscript, analysis of survey data and writing the manuscript. AP and HS revised the manuscript critically. All authors reviewed the final manuscript and contributed with comments and amendments and approved the final version.

Funding The authors have not declared a specific grant for this research from any funding agency in the public, commercial or not-for-profit sectors.

Competing interests AJ chairs the National Advisory Group on Suicide and Selfharm prevention to Welsh Government.

Patient and public involvement Patients and/or the public were not involved in the design, or conduct, or reporting, or dissemination plans of this research.

Patient consent for publication Not required.

Ethics approval As this study was a survey of usual service provision within the ambulance service, there was no requirement for institutional ethical approval as stated in the Health Research Authority website. https://www.hra.nhs.uk/approvalsamendments/what-approvals-do-i-need/research-ethics-committee-review/non-nhsresearch-projects/ (PAGE 5, 9)

Provenance and peer review Not commissioned; externally peer reviewed.

Data availability statement Data are available upon reasonable request. All data relevant to the study are included in the article or uploaded as supplementary information. Detailed survey anonymised questionnaire responses are available upon request from the corresponding author, however all responses are already summarised in table 1 included in the article.

Open access This is an open access article distributed in accordance with the Creative Commons Attribution Non Commercial (CC BY-NC 4.0) license, which permits others to distribute, remix, adapt, build upon this work non-commercially, and license their derivative works on different terms, provided the original work is properly cited, appropriate credit is given, any changes made indicated, and the use is non-commercial. See: http://creativecommons.org/licenses/by-nc/4.0/.

\section{ORCID iDs}

Mohammed Gaber Zayed http://orcid.org/0000-0001-9816-983X

Jenna Katherine Bulger http://orcid.org/0000-0002-1280-4941

\section{REFERENCES}

1 RCP. Royal college of Psychiatrists' report on self-harm, suicide and risk, 2010. Available: https://www.rcpsych.ac.uk/docs/default-source/improving-care/better-mhpolicy/college-reports/college-report-cr158.pdf [Accessed 01 Feb 2019].

2 Rees N, Rapport F, Snooks H, et al. How do emergency ambulance paramedics view the care they provide to people who self harm?: ways and means. Int I Law Psychiatry 2017:50:61-7.

3 Rees N, Rapport F, Thomas G, et al. Perceptions of paramedic and emergency care workers of those who self harm: a systematic review of the quantitative literature. J Psychosom Res 2014;77:449-56.

4 NICE. Self-Harm in over 8S: short-term management and prevention of recurrence. clinical guideline. Available: https://www.nice.org.uk/guidance/cg16 [Accessed $02 \mathrm{Feb}$ 2019].

5 Carter G, Page A, Large M, et al. Royal Australian and New Zealand College of Psychiatrists clinical practice guideline for the management of deliberate self-harm. Aust N Z J Psychiatry 2016:50:939-1000.

6 Bouveng O, Bengtsson FA, Carlborg A. First-Year follow-up of the psychiatric emergency response team (PAM) in Stockholm County, Sweden: a descriptive study. Int J Ment Health 2017;46:65-73.

7 Rees N, Rapport F, Snooks H. Perceptions of paramedics and emergency staff about the care they provide to people who self-harm: Constructivist metasynthesis of the qualitative literature. J Psychosom Res 2015;78:529-35.

8 Braun V, Clarke V. Using thematic analysis in psychology. Qual Res Psychol 2006;3:77-101.

9 Brown SN, Kumar D, James C, eds. UK ambulance services clinical practice guidelines. 2019 (JRCALC). Bridgwater: Class Professional, 2019.

10 NCCMH. National collaborating centre for mental health (UK). self-harm: the shortterm physical and psychological management and secondary prevention of self-harm in primary and secondary care. Leicester, UK: British Psychological Society, 2004. https://www.ncbi.nlm.nih.gov/books/NBK56398/pdf 